\title{
RNA Sequence Analysis of Growth-Related Genes in Penaeus monodon
}

\author{
Nifareesa CHEALOH ${ }^{1,2}$, Sataporn DIREKBUSARAKOM ${ }^{1,2}$, \\ Piyapong CHOTIPUNTU ${ }^{1,2}$, Pitchanee JARIYAPONG ${ }^{2,3}$, Hidehiro KONDO ${ }^{4}$, \\ Ikuo HIRONO ${ }^{4}$ and Suwit WUTHISUTHIMETHAVEE ${ }^{1,2, *}$
}

\author{
${ }^{1}$ School of Agricultural Technology, Walailak University, Nakhon Si Thammarat 80161, Thailand \\ ${ }^{2}$ Research Center of Excellence on Shrimp, Walailak University, Nakhon Si Thammarat 80161, Thailand \\ ${ }^{3}$ School of Medicine, Walailak University, Nakhon Si Thammarat 80161, Thailand \\ ${ }^{4}$ Laboratory of Genome Science, Graduate School of Marine Science and Technology, Tokyo University \\ of Marine Science and Technology, Minato, Tokyo 1088477, Japan
}

('Corresponding author's e-mail: suwitwuth@gmail.com)

Received: 25 April 2018, Revised: 14 June 2018, Accepted: 20 July 2018

\begin{abstract}
Penaeus monodon is one of the most economically important shrimp species in Thailand. However, little information is available about the functional genomics related to its growth performance. In this study, Illumina paired-end sequencing was used to analyze transcriptomes related to growth performance in P. monodon muscle. A total of 38.4 million reads were generated. The pooled reads, from 10 libraries, were de novo assembled into 113,991 genes, with an average length of $337 \mathrm{bp}$. Gene expression was analyzed with the edgeR program, which revealed 705 differentially expressed contigs $(p<0.05)$ in fastgrowth shrimp compared to slow-growth shrimp. The results show the 234 up-regulated contigs in fastgrowth shrimp are mostly underlined genes involving the metabolic pathway. Quantitative real-time polymerase chain reaction (qRT-PCR) revealed seven genes involved in the cell cycle that were expressed more in fast-growth shrimp $(p<0.05)$ than in slow-growth shrimp, and moderately to strongly correlated with shrimp body weight. These genes may be good candidates for growth performance improvement in P. monodon.
\end{abstract}

Keywords: Penaeus monodon, RNA sequencing, qRT-PCR, growth-related genes, growth improvement

\section{Introduction}

The shrimp farming industry began as inland aquaculture over 30 years ago in response to increasing consumption of and demand for shrimp worldwide. In 2007, the estimated global production of shrimp farms reached 3.36 million metric tons, with a value of over US\$14 billion [1]. In Southeast Asia, Thailand has been a major producer and exporter of farmed shrimp since 2015 [2]. Black tiger shrimp ( $P$. monodon) is one of the most economically important shrimp species in Southeast Asia, and is distributed throughout the Indo-Pacific region [3]. Current production of black tiger shrimp in Thailand has dramatically decreased due to a number of problems. One of the most significant of these is the slow growth performance of black tiger shrimp compared to other species, particularly Pacific white shrimp (Litopenaeus vannamei). However, black tiger shrimp has been long domesticated in Thailand, and shrimp growers are acquainted to their behavior; this makes renovation of black tiger shrimp culture in Thailand a challenge. Innovation and knowledge in improving growth performance are essential to reestablish the aquaculture industries of this species, not only in Thailand, but throughout the region.

Growth performance of shrimp is naturally dependent on internal, external [3,4], and genetic factors that contribute to phenotypic variation. The candidate genes potentially associated with individual growth performance have been reported in finfish [5] and Macrobrachium rosenbergii [6]. For P. monodon, 
http://wjst.wu.ac.th

expression analysis revealed growth-related candidate genes in the eyestalk and muscle [7,8]. While there are no available gene expression data to compare fast and slow growth in this species, this could be a useful tool to create direct strategies to improve growth performance.

Through transcriptome analysis using next-generation sequencing technology, which considers extensive gene expression and does not require prior knowledge of gene information [9], the growthrelated genes for fast and slow growth were identified in order to enrich and fill gaps in knowledge about the molecular information for P. monodon. The RNA sequence data were de novo assembled, and the gene abundances were estimated. The up-regulated contigs in fast-growth shrimp are mostly underlined genes involving the metabolic pathway. The selected gene participates in the cell cycle was found to be moderately to strongly correlated with shrimp body weight and may be a good candidate gene for growth performance improvement in P. monodon.

\section{Materials and methods}

\section{Sample collection and RNA extraction}

Specific-pathogen-free P. monodon (four months of age) were reared and collected from the Shrimp Quarantine Center, Walailak University. First, the body weight and body length of 50 individual shrimp at 4 months old were recorded, and the mean and standard deviation were determined and used as criteria to divide the shrimp into two groups (fast-growth group: shrimp $>$ mean $+\mathrm{sd}$, and slow-growth group: shrimp $<$ mean + sd). Muscle tissue was collected from five shrimp specimens in each group and individually separated for next-generation sequencing (NGS) analysis. Total RNA was extracted from shrimp muscle tissue using TriPure Isolation Reagent ${ }^{\mathbb{B}}$ (Roche, Basel, Switzerland). The tissue samples were ground in liquid nitrogen and mixed with TriPure Isolation Reagent ${ }^{\circledR}$. Phenol-chloroform was then added to the suspension to separate DNA and protein from the RNA sample. Total RNA was precipitated using isopropanol, washed with ethanol, and digested with DNase treatment to eliminate contaminated genomic DNA. After centrifugation, the RNA was dried and used for NGS and quantitative RT-PCR.

\section{Gene expression profiling analysis}

mRNA was isolated from individual DNase-treated total RNA using a Truseq RNA sample preparation kit (Illumina, San Diego, U.S.A.) according to the manufacturer's low-throughput protocol instruction. The cDNA library, with fragment sizes of about $\sim 240 \mathrm{bp}$ and different barcodes from 10 individual libraries, was pooled and sequenced on the Illumina MiSeq platform (Illumina, San Diego, California, U.S.A.). All sequence reads were filtered with trimmomatic software to remove adapter sequencing and very short sequences [10]. Sequence reads were combined from all 10 libraries and de novo assembled into contigs using the Trinity software [11]. The sequence reads were assembled using default parameters with a k-mer of 25 to generate the transcriptome assembled contigs [12]. Reads from individual shrimp samples were mapped onto the assembled contigs using the Bowtie program. Gene abundances were determined by the gene count number using RSEM software [13]. The gene count data of each library from fast-growth and slow-growth shrimp were used to detect the differential expressed genes. The Exact test was used to identify differentially expressed genes across samples in the two groups and normalize the number of counts per million reads [14-17], using the support tool from Blast2GO bioinformatics software [18]. Statistical tests at $p$-value $<0.05[19,20]$ and calculated fold changes were included for candidates of differential gene expression. The differentially expressed genes were annotated with Blast2GO bioinformatics software version 4.0. The blast-hit results were mapped to gene ontology to identify their function and improve the protein domain information with InterPro annotation (http://www.ebi.ac.uk/ interpro/search) [21-23]. The pathways of differentially expressed genes were predicted by the Kyoto Encyclopedia of Genes and Genome (KEGG) (http://www.genome.jp/kegg) $[15,19,24]$. 
Validation of differential gene expression by quantitative RT-PCR

Specific primers for high differentially expressed genes between fast-growth and slow-growth shrimp were designed based on contig sequences using the Primer 3 program (http://frodo.wi.mit.edu/cgibin/primer3/primer3) (Table 1). Individual body weight from 20 shrimps in each group were recorded. Muscle tissue was collected for individual RNA extraction. The purified DNase I-treated total RNA was subjected to cDNA synthesis using the iScript Select cDNA Synthesis Kit according to the manufacturer's instructions (Bio-rad, California, USA). The quantitative PCR (qPCR) reaction contained $20 \mathrm{ng}$ of total RNA equivalent, 1x HOT FIREPol Evagreen qPCR Mix Plus $(2.5 \mathrm{nM} \mathrm{MgCl}$ ), and 100 $250 \mathrm{nM}$ forward and reverse primer, respectively. The amplification profile included an initial denaturation step at $95^{\circ} \mathrm{C}$ for $15 \mathrm{~min}$ and 40 cycles of $95^{\circ} \mathrm{C}$ for $15 \mathrm{~s}, 50-60^{\circ} \mathrm{C}$ for $15 \mathrm{~s}$, and $72{ }^{\circ} \mathrm{C}$ for 30 s using the Applied Biosystems 7300 Real-Time PCR System (Applied Biosystems). Beta-actin (GenBank accession no. JQ241179.1) was used as the reference gene. The melting curves were directly plotted from ABI-7300 software (Applied Biosystems). The obtained cycle threshold (Ct) values were calculated by the relative expression ratio. Relative mRNA expression of fast-growth and slow-growth shrimp were calculated using the real-time PCR Ct method with qPCR efficiencies $\left(E=10^{[-1 / \text { slope }]}\right)[25,26]$. PCR efficiency was determined by creating standard curves from five-fold serial dilutions from the pooled total RNA ( $\mathrm{n}=5$ for each group). qPCR was performed using SPSS Statistical Package version 17 (Chicago, IL, USA), and statistical significance was set at $p<0.05$. $t$-tests were performed to compare growth performance between the groups of shrimps. The mRNA expression values of the groups of shrimp were compared using non-parametric comparisons from the Mann-Whitney U-test [27,28]. Correlations between relative gene expression and shrimp body weight were analyzed using Pearson's correlation and the corresponding probability values at $p<0.05$.

Table 1 List of the candidate genes and primer sequences for qPCR analysis.

\begin{tabular}{|c|c|c|c|c|}
\hline Contig & BLASTX annotation & Primer sequences (5' to $3^{\prime}$ ) & Melting temperature & qPCR Efficiency \\
\hline \multirow[t]{2}{*}{$\mathrm{c} 32943 \mathrm{~g} 1$} & Cyclin A & TGTCGACTGGCTTGTTGAAG & 89.0 & 1.88 \\
\hline & (Penaeus monodon) & TCTCCTCATATTTCGCAGCA & & \\
\hline \multirow[t]{2}{*}{ c34539g1 } & Cyclin B & TGGAAGTGCTACATTTTGAACG & 84.7 & 1.82 \\
\hline & (Litopenaeus vannamei) & ACACCTTGGGAAGATCATGG & & \\
\hline \multirow[t]{2}{*}{ c23687g2 } & Peritrophin & CGAACTGGTAAATGCAAGGA & 85.1 & 2.02 \\
\hline & (Fenneropenaeus chinensis) & ATGCACTGTTTCTGGGGTCT & & \\
\hline \multirow[t]{2}{*}{ c34027g2 } & Polehole-like protein & GGTTTCCATGGTCATCCATC & 83.7 & 1.85 \\
\hline & (Penaeus monodon) & CTGCTCCAACATCAGTGGAA & & \\
\hline \multirow[t]{2}{*}{$\mathrm{c} 34340 \mathrm{~g} 1$} & Uncharacterized protein & GGAGACCGTGACGAGGAC & 90.1 & 1.81 \\
\hline & (Hyalella azteca) ; Amphipod & AAACCGGTGTGGTGGTAAC & & \\
\hline \multirow[t]{2}{*}{$\mathrm{c} 23687 \mathrm{~g} 1$} & Unknown gene & TGAGACACAATCGAAGTTCAGG & 78.6 & 1.86 \\
\hline & & AGACACCCGATAAGTGGACC & & \\
\hline \multirow[t]{2}{*}{$\mathrm{c} 25370 \mathrm{~g} 1$} & Unknown gene & AGCCCAGTAGTGGTCTGTGG & 90.2 & 1.90 \\
\hline & & TGTAGTTCCCTCCTGCTGCT & & \\
\hline
\end{tabular}


http://wjst.wu.ac.th

\section{Results and discussion}

RNA sequencing and de novo assembly

Five shrimps per group were collected for NGS analysis; their growth data are presented in the Table 6. The results of Illumina paired-end sequencing and read processing from fast-growth and slowgrowth shrimp were 37,272,958 and 37,270,669 raw reads, before and after trimming, respectively (Table 2). The clean reads were submitted to the SRA database (https://www.ncbi.nlm. nih.gov/sra/SRP132755, SRA accession: SRP132755). All clean reads from 10 cDNA libraries were merged and de novo assembled using the Trinity program into 117,265 contigs with a total length of 40,813,691 nt. The median and average contig length were $264 \mathrm{bp}$ and $384 \mathrm{bp}$, respectively. From cluster analysis, 113,991 genes were obtained from 38,474,021 bp with an average length of 337.52 bp (Table 3). Figure 1 shows the sequence length distribution of genes and transcripts in this study.

Table 2 Summary of NGS data.

\begin{tabular}{lll}
\hline & Slow growth & Fast growth \\
\hline Before trimming & & \\
Number of reads & $19,289,140$ & $17,983,818$ \\
Sequence length (bp) & $35-151$ & $35-151$ \\
Percent of GC & 39.9 & 42.2 \\
After trimming & & \\
Number of reads & $19,288,354$ & $17,982,315$ \\
Sequence length (bp) & $36-151$ & $36-151$ \\
Percent of GC & 39.9 & 42.2 \\
Percent of remaining & 99.9 & 99.9 \\
\hline
\end{tabular}

Table 3 Summary statistics of de novo assembled data.

\begin{tabular}{lrr}
\hline & Transcripts & Genes \\
\hline Total number (contigs) & $117,265.00$ & $113,991.00$ \\
N50 (b) & 320.00 & 312.00 \\
Median length (b) & 264.00 & 263.00 \\
Average length (b) & 348.05 & 337.52 \\
Maximum length (b) & 10980.00 & 10953.85 \\
Minimum length (b) & 201.00 & 201.00 \\
Total assembled bases (b) & $40,813,691.00$ & $38,474,021.00$ \\
\hline
\end{tabular}


http://wjst.wu.ac.th

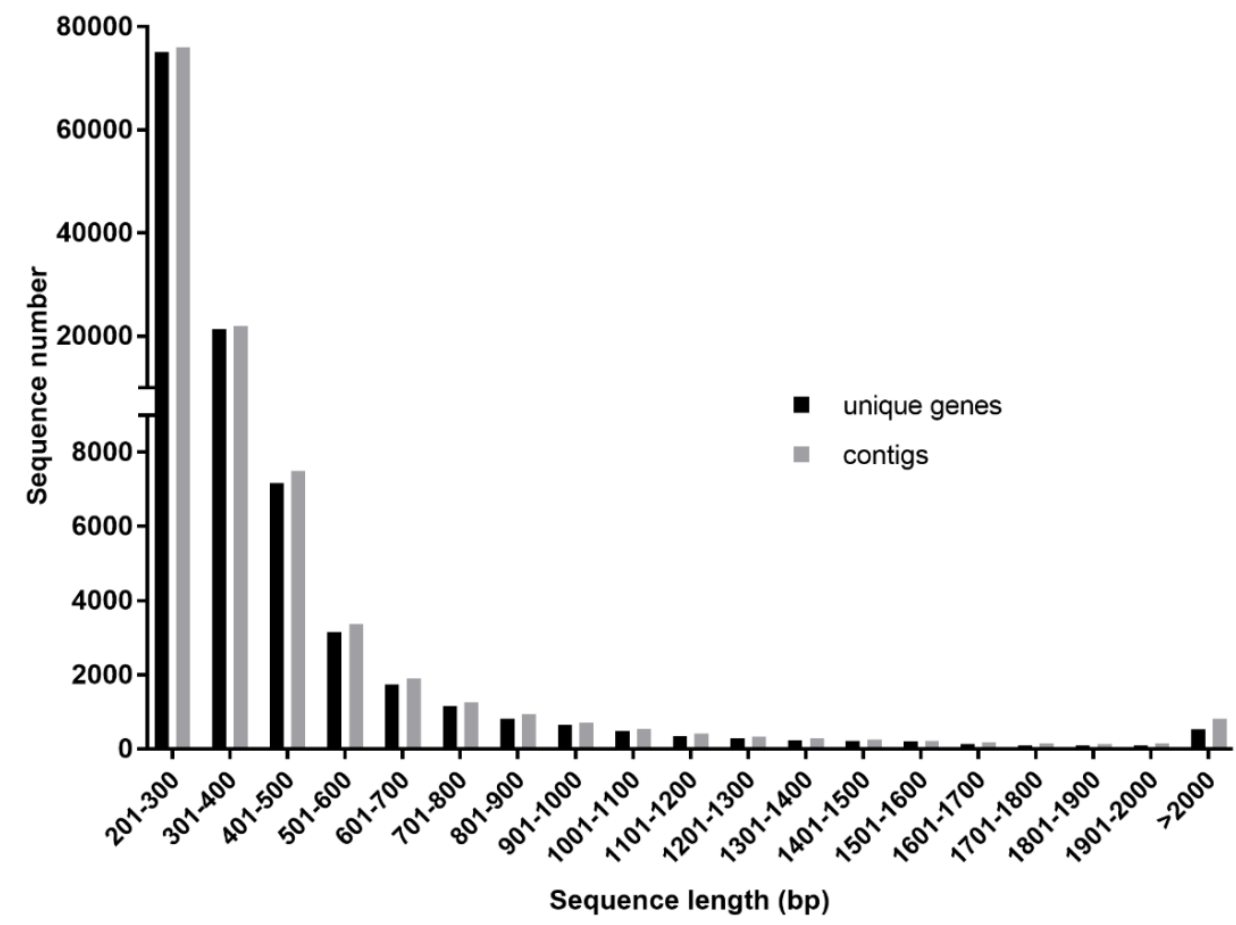

Figure 1 Length distribution of de novo assembled genes and transcripts of $P$. monodon.

\section{Differentially expressed genes}

Individual gene count data between the two groups were compared using the edgeR program. A total of 705 unique genes demonstrated differentially expressed value between fast-growth and slowgrowth shrimp ( $p$-value $<0.05)$ which contained 234 up-regulated genes and 471 down-regulated genes in fast-growth P. monodon. Alternatively, the genes that matched the threshold False discovery rate $($ FDR $)<0.001$ were adjusted as high differentially expressed genes (17 up-regulated and two downregulated genes) and used for qRT-PCR analysis (Table 4).

Table 4 Summary of differentially expressed genes annotation analysis.

\begin{tabular}{lcc}
\hline & Genes & Contigs \\
\hline Cut of at $p$-value $<0.05$ & & \\
Up-regulated genes & $234(33.2 \%)$ & $324(34.9 \%)$ \\
Down-regulated genes & $471(66.8 \%)$ & $605(65.1 \%)$ \\
Total & $\mathbf{7 0 5}$ & $\mathbf{9 2 9}$ \\
\hline Cut of at FDR $<0.001$ & & \\
Up-regulated genes & 17 & \\
Down-regulated genes & 2 & \\
Total & $\mathbf{1 9}$ & \\
\hline
\end{tabular}


http://wjst.wu.ac.th

Gene ontology analysis

A BLASTX search was performed for each set of up-regulated and down-regulated genes in fastgrowth $P$. monodon. After alignment against the NCBI non-redundant (nr) protein database at a cut-off $E$ value $\leq 1 \mathrm{E}-5$, most sequences matched genes of crustaceans or insects, such as $P$. monodon, Hyalella Azteca (amphipod crustacean), Fenneropenaeus chinensis (Chinese white shrimp), Pediculus humanus corporis (louse), or Zootermopsis nevadensis (eusocial termite) (Figure 2).

\section{Up-regulated gene in fast growth}

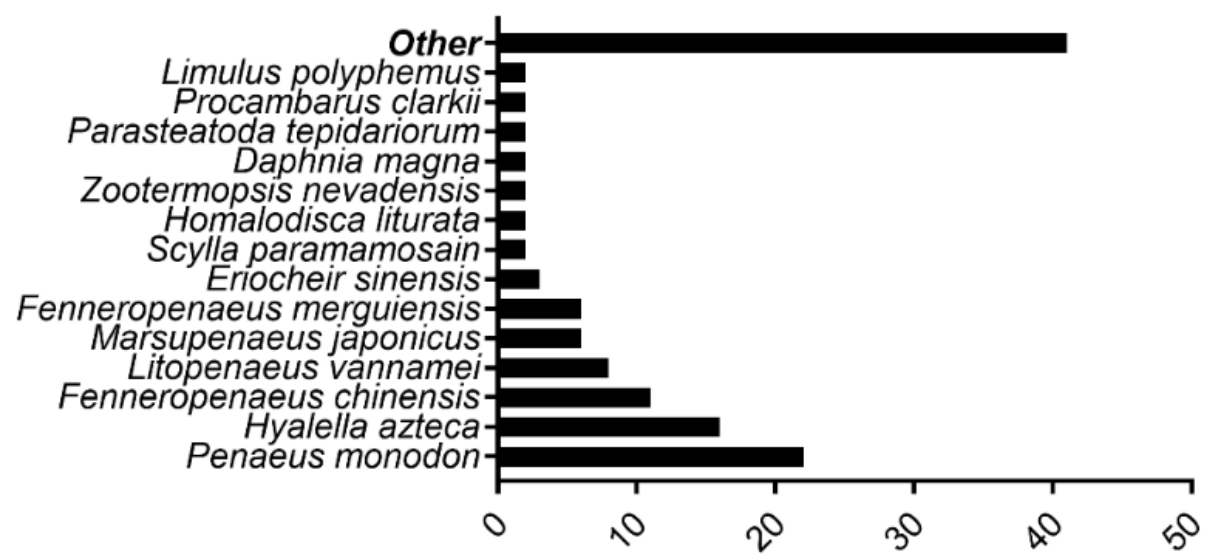

Down-regulated gene in fast growth

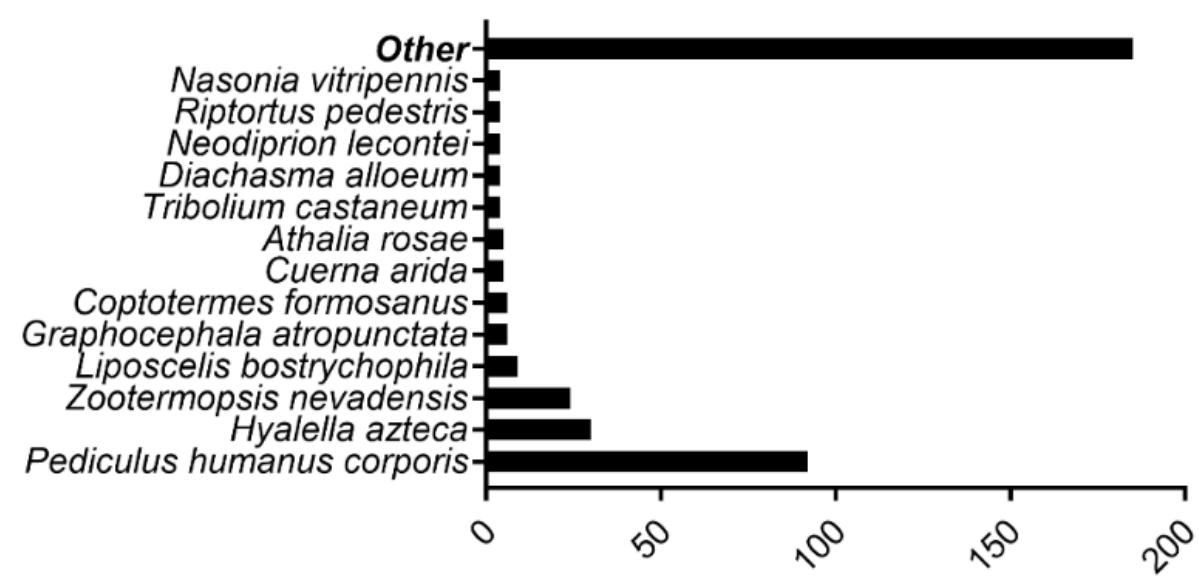

Figure 2 Species distribution searches against the database. 
Table 5 List of protein domain prediction in up-regulated and down-regulated genes.

\begin{tabular}{|c|c|c|c|}
\hline IPR accession number & Description & Protein type & Expression \\
\hline IPR001304; IPR016186; IPR016187 & C-type lectin-like; C-type lectin-like/link domain; C-type lectin fold & domain & up \\
\hline IPR008197 & WAP-type 'four-disulfide core' domain & domain & up \\
\hline IPR024509; IPR024716 & Anti-lipopolysaccharide factor/Scygonadin; Anti-lipopolysaccharide factor & family & up \\
\hline IPR000867 & Insulin-like growth factor-binding protein, IGFBP & domain & up \\
\hline IPR009030 & Growth factor receptor cysteine-rich domain & domain & up \\
\hline IPR011390 & Insulin-like growth factor binding protein-related and protein (IGFBP-rP) & family & up \\
\hline IPR002181; IPR014715; IPR014716 & Fibrinogen, alpha/beta/gamma chain, C-terminal globular domain; subdomain $1 ; 2$ & domain & up \\
\hline IPR002557 & Chitin binding domain & domain & up, down \\
\hline IPR012336 & Thioredoxin-like fold & domain & up, down \\
\hline IPR001254; IPR009003 & Serine proteases, trypsin domain; Peptidase S1, PA clan & domain & up, down \\
\hline IPR018114 & Serine proteases, trypsin family, histidine active site & active site & up, down \\
\hline IPR001314 & Peptidase S1A, chymotrypsin family & family & up, down \\
\hline IPR027417 & P-loop containing nucleoside triphosphate hydrolase & domain & down \\
\hline IPR008991 & Translation protein SH3-like domain & domain & down \\
\hline IPR012340; IPR014722 & Nucleic acid-binding, OB-fold; Ribosomal protein L2 domain 2 & domain & down \\
\hline IPR010987 & Glutathione S-transferase, C-terminal-like & domain & down \\
\hline IPR011332 & Zinc-binding ribosomal protein & domain & down \\
\hline IPR016040 & $\mathrm{NAD}(\mathrm{P})$-binding domain & domain & down \\
\hline IPR004045; IPR004046 & Glutathione S-transferase, N-terminal; C-terminal & domain & down \\
\hline IPR009000 & Translation protein, beta-barrel domain & domain & down \\
\hline IPR000859 & CUB domain & domain & down \\
\hline
\end{tabular}

A total of 175 of 234 up-regulated genes and 389 of 471 down-regulated genes were matched to known proteins in the InterPro database. Table 5 presents the protein domains adjusted by a high number of matched genes. Insulin-like growth-factor-binding protein, growth-factor receptor cysteine-rich domain, and insulin-like growth-factor binding protein-related protein (IGFBP-rP) up-regulation were presented in fast-growth $P$. monodon. Interestingly, proteins including C-type lectin-domain and antilipopolysaccharide factor, which play a role in immunity, were found to be up-regulated in this study.

The GO term at level 2 was classified into three sub-ontologies (Figure 3). The up-regulated genes were mapped into five molecular function categories. Most of the proteins involved in binding, catalytic activity, and the top of the biological process are metabolic and cellular processes. Furthermore, direct GO analysis revealed that most genes encode protein involved in the binding function, while genes involved in biological processes encode protein involved in the chitin metabolic process, cell adhesion, and regulation of cell growth (Figure 4). Based on the KEGG pathway, up-regulated genes in fast-growth shrimp are well-represented in metabolism pathways. 
http://wjst.wu.ac.th

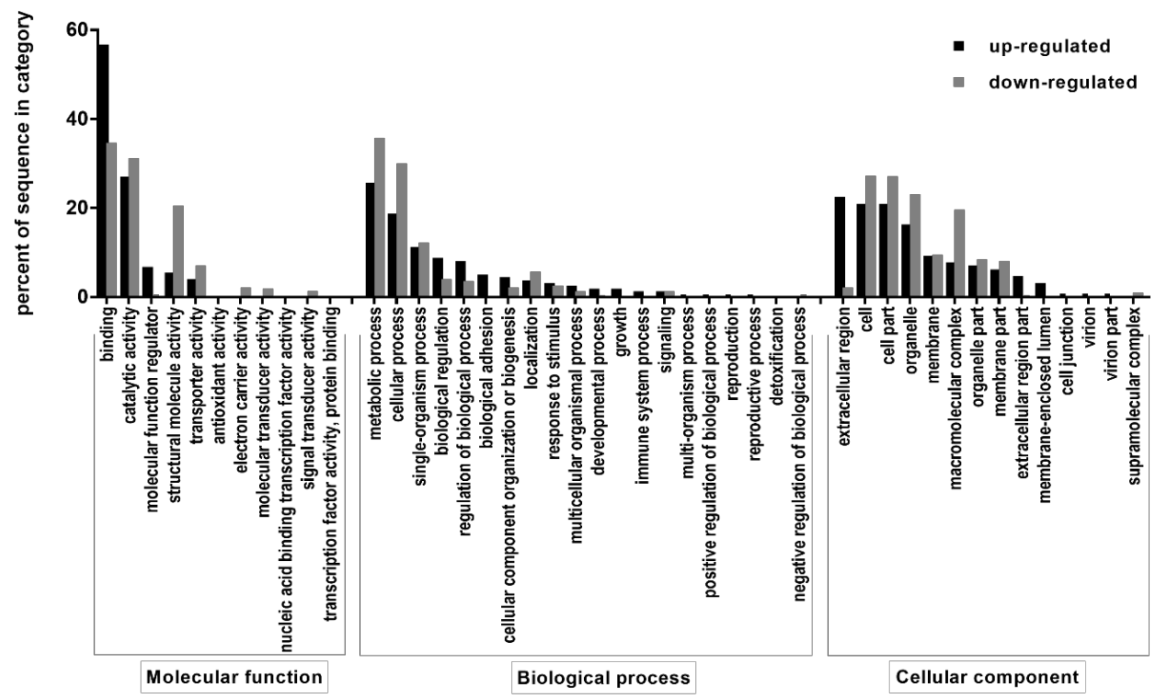

Figure 3 Gene ontology (level 2) of up-regulated and down-regulated genes in fast-growth P. monodon.
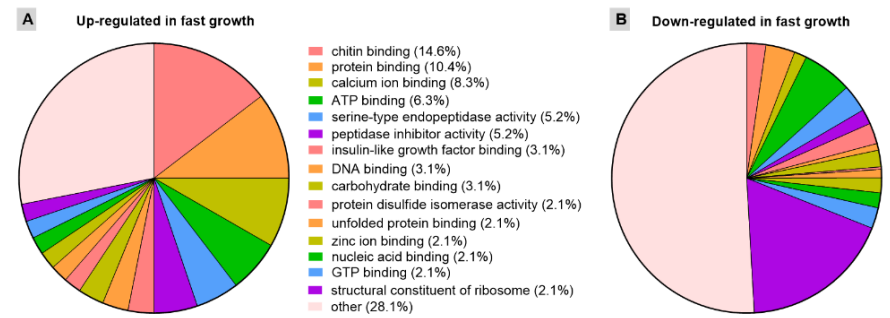

Ehitn binding $(2.3 \%)$
protein binding $(3.5 \%)$
calcium ion binding (1.5\%)

= ATP binding (6.0\%)

- serine-type endopeptidase activity $(3.3 \%)$
translation elongation factor activity $(1.8 \%)$

- translation elongation
RNA binding $\left(25^{\circ}\right.$ )

$=$ DNA binding $(0.8 \%)$

= cytochrome-coxidase activity (2.0\%)

- protein disulfide isomerase activty
$=$ unfolded protein binding $(1.0 \%)$

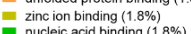

(ling $1.8 \%)$

C Up.regulated in fast growth

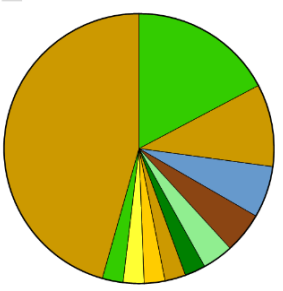

Chitin metabolic process $(17.3 \%$

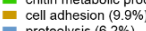

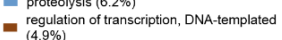

$=2$ rogulation of of cell growth $(3.7 \%$ )

- coll redox hom oostasis (2.5\%)

$=$ oxidation-reduction process $(2.5 \%)$
transport $(2.5 \%)$

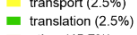

$=$ other (45.7\%)

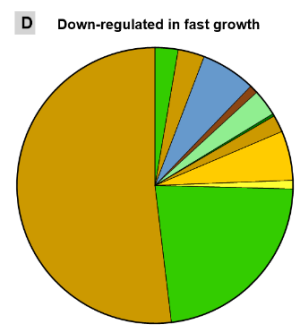

E- chitin metabolic process $(2.7 \%)$
translational elongation $(3.1 \%)$

- regulation of transcription, DNA-templated

ATP synthesis coupled prolon transport

= cell redox homeostasis $(0.3 \%)$

protein folding $(2.0 \%)$
oxidation-reduction process $(5.8 \%)$

transport $(1.0 \%)$

$=$ transiation $(22.7 \%)$
other $(51.9 \%)$
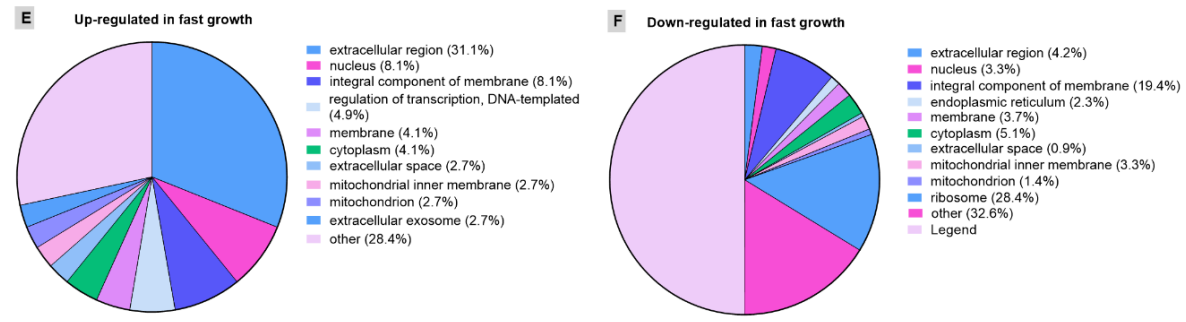

Figure 4 Gene ontology categorization of up-regulated and down-regulated genes in fast-growth $P$. monodon; molecular function (A, B), biological process (C, D), and cellular component category (E, F). 
http://wjst.wu.ac.th

Table 6 Averages of growth data between fast growth and slow growth $P$. monodon for qPCR analysis.

\begin{tabular}{lcc}
\hline & Body weight $(\mathbf{g})$ & Body length (cm) \\
\hline Slow growth & $2.53 \pm 0.56^{\mathrm{b}}$ & $5.51 \pm 0.43^{\mathrm{b}}$ \\
Fast growth & $13.50 \pm 3.86^{\mathrm{a}}$ & $9.42 \pm 0.98^{\mathrm{a}}$ \\
$p$-value & 0.000 & 0.000 \\
\hline
\end{tabular}

* Mean \pm SD having the same superscript in the same column are not significantly different at $95 \%$ confident interval of independent-sample $t$-test at $p$-value $<0.05$.

\section{Quantitative PCR validation}

Quantitative PCR validation was performed in two groups of shrimp. The individual body weight of $P$. monodon of each group in average data between fast-growth and slow-growth was significantly different $(p<0.05)$ (Table 6). The qRT-PCR results show that seven candidate genes are highly expressed in fast-growth shrimp compared to slow-growth shrimp. These seven genes, namely cyclin-A, cyclin-B, peritrophin, polehole-like protein, uncharacterized gene I, unknown gene I, and unknown gene III, were found to be significantly highly up-regulated $(p<0.05)$ (Figure 5). Moreover, the mRNA levels of six genes, namely cyclin A, cyclin B, peritrophin, polehole-like protein, uncharacterized protein I, and unknown gene I $(p<0.05)$, were found to be significantly expressed and correlated with growth performance (Table 7).
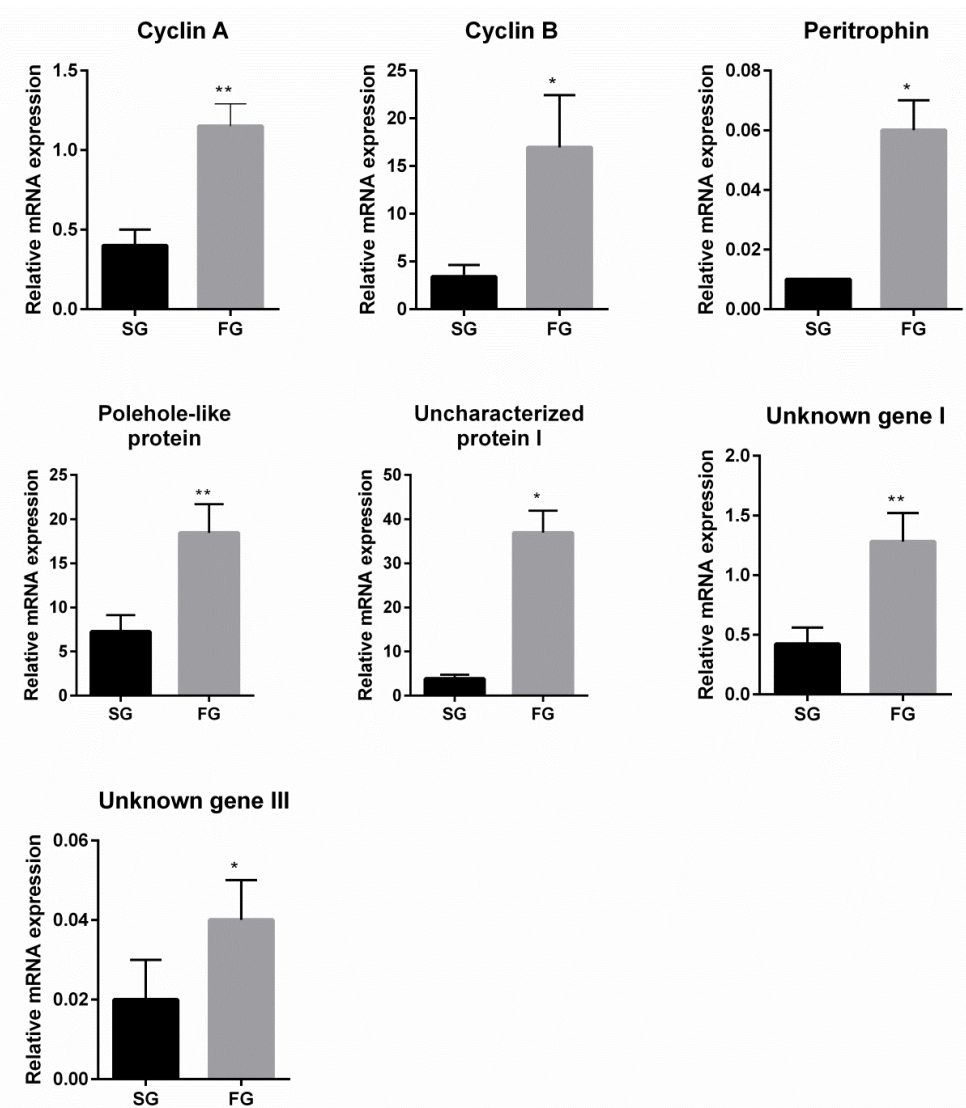

Figure 5 qRT-PCR validation results of candidate genes from RNA sequencing of fast-growth (FG) and slow-growth (SG) P. monodon. These data are expressed as the mean \pm SEM. ${ }^{*} ; p<0.05, * * ; p<0.01$. 
http://wjst.wu.ac.th

Table 7 Correlation results of relative mRNA expression levels and shrimp body weights.

\begin{tabular}{lccc}
\hline BLASTX annotation & Contig number & $\mathbf{r}^{\mathbf{a}}$ & $\boldsymbol{p}^{\text {-value }}$ va $^{\mathbf{b}}$ \\
\hline Cyclin A & $\mathrm{c} 32943 \mathrm{~g} 1$ & $0.728^{* *}$ & 0.005 \\
Cyclin B & $\mathrm{c} 34539 \mathrm{~g} 1$ & $0.568^{*}$ & 0.034 \\
Peritrophin & $\mathrm{c} 23687 \mathrm{~g} 2$ & $0.677^{* *}$ & 0.008 \\
Polehole-like protein & $\mathrm{c} 34027 \mathrm{~g} 2$ & $0.520^{*}$ & 0.027 \\
Uncharacterized protein I & $\mathrm{c} 34340 \mathrm{~g} 1$ & $0.640^{*}$ & 0.014 \\
Unknown gene I & $\mathrm{c} 23687 \mathrm{~g} 1$ & $0.553^{*}$ & 0.032 \\
\hline
\end{tabular}

${ }^{a}$ Correlation value: 0.00 - 0.19; very weak, 0.20 - 0.39; weak, 0.40 - 0.59; moderate, 0.60 - 0.79; strong, 0.80 - 1.00; very strong.

${ }^{\mathrm{b}} p$-value accepted as significantly different at $p<0.05$.

\section{Discussion}

High-throughput RNA sequencing technologies have been used to create a reference to guarantee coverage of transcript detection [29,30]. RNA may be differentially expressed according to the tissue, stage of development, and the physiological condition in which they are accessed [30]. In this study, we focus on differentially expressed genes from P. monodon muscle, which is the main organ contributing to the weight and growth of shrimp [31]. RNA from the abdominal muscle of fast-growth and slow-growth shrimp was sequenced using Illumina MiSeq. The Trinity de novo assembly generated 113,991 genes with an average length of $337.52 \mathrm{bp}$. The difference in sequence quality is fundamentally dependent on the sample size and the sampled tissue. Equally mixed RNA from different tissues and specimens was utilized for transcriptome sequencing to obtain as many gene transcripts as possible and avoid the negative effects of individual variation [24,32]. However, the excessive number of samples presents disadvantages related to the quality of assembled sequences due to individual variation. This results in more unigenes but shorter average length, which may be partly caused by the different de novo assembler $[19,33]$. The Trinity assembly software used in this study performed consistently well [34] across the mentioned problems. Identification of protein domain for annotated transcriptome showed some sequences have roles in growth, including insulin like-growth and fibrinogen [8]. Regarding GO categories, our results correspond well with earlier studies on penaeid shrimp [19,33,35]. Focusing on fast-growth shrimp, the up-regulated genes were categorized by peptidase inhibitor activity and protein binding function. Most down-regulated gene expression is associated with structural molecule activity (ribosome). These differentially expressed candidate genes, which are highly expressed in fast-growth shrimp, may play important roles in promoting growth in P.monodon. Based on the KEGG database, the information is related to the metabolic pathways, which are involved in general metabolism, spliceosomes, RNA transport, phagosomes, and antioxidants [19,33,36].

Our prime interest, the genes that were observed to be highly expressed in fast-growth shrimp and related to shrimp body weight, were cyclin A, cyclin B, polehole-like protein, and peritrophin. In animal subjects, cyclins have been shown to have functional roles in cell cycle regulation [37]. Cyclins A and B have distinct, specialized roles in the cell cycle, but in all cells, both have a function in the regulation of mitotic control [38]. Cyclins A and B have been characterized in P. monodon (PMCyA and PMCyB) during ovarian development and spawning in normal shrimp broodstock [39]. Temporal expression of the cyclin B gene in various organs, including the liver, ovaries, muscle tissue, brain, stomach, and heart, indicate that it may play a key role in the cell division stage [40].

The polehole gene was first identified in drosophila [41]. The expression of this gene plays a fundamental role in dividing larval cells and may be linked to receptor tyrosine kinase (RTK) [42], which is an important mechanism linking the extracellular signal process in cell growth and differentiation to changes in gene expression and cell behavior $[43,44]$. It has also been identified as being involved in ovarian development of Portunus trituberculatus (swimming crab) [45]. The up-regulation of the gene in 
http://wjst.wu.ac.th

fast-growth shrimp demonstrates the mechanism of this gene in cell proliferation, which is related to growth performance in P.monodon. The peritrophin gene, one of the components of the peritrophic matrix, was first isolated in the intestines of insects [46] and plays an important role in stimulating the digestion of food and providing protection from microorganisms [46,47]. In crustaceans, this protein is called shrimp ovarian peritrophin (SOP) and has been reported as a component of the egg layer in P.semisulcatus (marine shrimp) because it assists in the formation of a protective layer around eggs immediately after fertilization [48]. SOP has also been isolated from the oocytes of M. japonicas, P. monodon, and F. merguiensis [49-51]. Interestingly, peritrophin-like proteins were found to be highly expressed in fast-growth shrimp in this study, suggesting that this gene may not only be involved in ovarian development but also be related to growth development of shrimp.

The characterization of candidate genes involved in the growth of black tiger shrimp has been studied before. Eyestalk tissue from mature female shrimp (7 months old shrimp) was used in suppressive subtractive hybridization (SSH). Cyclophilin, fibrillarin, SPARC, and PC2 were reported as being involved in cell cycle and cell differentiation; they showed negative correlation with shrimp body weight [7]. In this study, we focused on positively correlated genes with growth of juvenile shrimp. The upregulation genes involved in the cell cycle and cell division were also observed, such as cyclin A and cyclin B; from statistical analysis, they presented positive correlation to shrimp body weight. This is as per another study [8]; the genes from shrimp muscle tissue were observed, such as actin, profilin, and myosin genes. However they were not significantly different between groups of shrimp.

The up-regulation of unidentified genes in other animals or shrimp in this study may also be important for growth performance and should be further studied to develop markers related to the growth of $P$. monodon. From this study, concerning other highly expressed genes in fast-growth shrimp from the metabolic pathway, biological process, and domain in protein, from the NGS results, some of these were reported as being possibly involved with growth in other animals; these also will be further studied to obtain more information and understanding.

\section{Conclusions}

In the present study, transcriptome analysis of abdominal muscle in fast-growth and slow-growth $P$. monodon was performed using the RNA sequencing technique. De novo assembly resulted in 113,991 genes with an average length of $337.52 \mathrm{bp}$ and transcriptome coverage of about $38.47 \mathrm{Mb}$. A comparison of gene expression between fast-growth and slow-growth shrimp revealed a total of 705 genes, including 234 up-regulated and 471 down-regulated genes $(p<0.05)$. Quantitative RT-PCR revealed highly expressed genes in fast-growth shrimp, namely the cyclin A and cyclin B genes, peritrophin gene, and polehole-like protein gene, all of which are related to growth performance. Moreover, the interesting gene ontology established in molecular functional protein binding is related to biological processes such as the cell regulation of cell growth. All of these are candidate genes for further study to develop a marker for growth performance detection in $P$. monodon.

\section{Acknowledgement}

This research was supported by the Program Strategic Scholarships Fellowships Frontier Research Networks (Specific for Southern Region) for the Ph.D. Program, from the Office of the Higher Education Commission, Thailand, and also by the Research Center of Excellence on Shrimp. 
http://wjst.wu.ac.th

\section{References}

[1] M Saroglia and Z Liu. Functional Genomics in Aquaculture. Wiley, 2012, p. 1-403.

[2] FAO. The State of World Fisheries and Aquaculture 2016. Food and Agriculture Organization of the United Nations, 2016.

[3] AW Fast and LJ Lester. Marine Shrimp Culture: Principles and Practices. Elsevier, 1992, p. 879.

[4] H Jung, RE Lyons, DA Hurwood and PB Mather. Genes and growth performance in crustacean species: A review of relevant genomic studies in crustaceans and other taxa. Rev. Aquaculture 2013; 5, 77-110.

[5] C De-Santis and DR Jerry. Candidate growth genes in finfish: Where should we be looking? Aquaculture 2007; 272, 22-38.

[6] H Jung, RE Lyons, Y Li, NM Thanh, H Dinh, DA Hurwood, KR Salin and PB Mather. A candidate gene association study for growth performance in an improved giant freshwater prawn (Macrobrachium rosenbergii) culture line. Mar. Biotechnol. 2014; 16, 161-80.

[7] A Tangprasittipap, M Tiensuwan and B Withyachumnarnkul. Characterization of candidate genes involved in growth of black tiger shrimp Penaeus monodon. Aquaculture 2010; 307, 150-6.

[8] C Nguyen, TG Nguyen, LV Nguyen, HQ Pham, TH Nguyen, HT Pham, HT Nguyen, TT Ha, TH Dau, HT Vu, DD Nguyen, NTT Nguyen, NH Nguyen, DV Quyen, HH Chu and KD Dinh. De novo assembly and transcriptome characterization of major growth-related genes in various tissues of Penaeus monodon. Aquaculture 2016; 464, 545-53.

[9] CA Santos, DV Blanck and PD de Freitas. RNA-seq as a powerful tool for penaeid shrimp genetic progress. Front. Genet. 2014; 5, 1-6.

[10] AM Bolger, M Lohse and B Usadel. Trimmomatic: A flexible trimmer for Illumina sequence data. Bioinformatics 2014; 30, 2114-20.

[11] MG Grabherr, BJ Haas, M Yassour, JZ Levin, DA Thompson, I Amit, X Adiconis, L Fan, R Raychowdhury, Q Zeng, Z Chen, E Mauceli, N Hacohen, A Gnirke, N Rhind, FD Palma, BW Birren, C Nusbaum, K Lindblad-Toh, N Friedman and A Regev. Full-length transcriptome assembly from RNA-Seq data without a reference genome. Nat. Biotechnol. 2011; 29, 1-11.

[12] J Feng, W Li and T Jiang. Inference of isoforms from short sequence reads. J. Comput. Biol. 2011; 18, $1-21$.

[13] B Li and CN Dewey. RSEM: Accurate transcript quantification from RNA-Seq data with or without a reference genome. BMC Bioinformatics 2011; 12, 1-16.

[14] M-A Dillies, A Rau, J Aubert, C Hennequet-Antier, M Jeanmougin, N Servant, C Keime, G Marot, D Castel, J Estelle, G Guernec, B Jagla, L Jouneau, D Laloë, C Le Gall, B Schaëffer, SL Crom, M Guedj and F Jaffrézic. A comprehensive evaluation of normalization methods for Illumina highthroughput RNA sequencing data analysis. Briefings Bioinformatics 2013; 14, 671-83.

[15] S Li, X Zhang, Z Sun, F Li and J Xiang. Transcriptome analysis on Chinese shrimp Fenneropenaeus chinensis during WSSV acute infection. PLoS One 2013; 8, 1-15.

[16] C Trapnell, BA Williams, G Pertea, A Mortazavi, G Kwan, MJ van Baren, SL Salzberg, BJ Wold and L Pachter. Transcript assembly and quantification by RNA-Seq reveals unannotated transcripts and isoform switching during cell differentiation. Nat. Biotechnol. 2010; 28, 511-18.

[17] BJ Haas, A Papanicolaou, M Yassour, M Grabherr, PD Blood, J Bowden, MB Couger, D Eccles, B Li, M Lieber, MD MacManes, M Ott, J Orvis, N Pochet, F Strozzi, N Weeks, R Westerman, T William, CN Dewey, R Henschel, RD LeDuc, N Friedman and A Regev. De novo transcript sequence reconstruction from RNA-Seq: Reference generation and analysis with Trinity. Nat. Protocol. 2013; 8, 1-43.

[18] MD Robinson, DJ McCarthy and GK Smyth. edgeR: A bioconductor package for differential expression analysis of digital gene expression data. Bioinformatics 2010; 26, 1-2.

[19] S Sookruksawong, F Sun, Z Liu and A Tassanakajon. RNA-Seq analysis reveals genes associated with resistance to Taura syndrome virus (TSV) in the Pacific white shrimp Litopenaeus vannamei. Dev. Comp. Immunol. 2013; 41, 523-33. 
http://wjst.wu.ac.th

[20] J Gao, X Wang, Z Zou, X Jia, Y Wang and Z Zhang. Transcriptome analysis of the differences in gene expression between testis and ovary in green mud crab (Scylla paramamosain). BMC Genomics 2014; 15, 1-15.

[21] H Jung, RE Lyons, H Dinh, DA Hurwood, S McWilliam and PB Mather. Transcriptomics of a giant freshwater prawn (Macrobrachium rosenbergii): De novo assembly, annotation and marker discovery. PLoS One 2011; 6, 1-14.

[22] A Conesa, S Gotz, JM Garcia-Gomez, J Terol, M Talon and M Robles. Blast2GO: A universal tool for annotation, visualization and analysis in functional genomics research. Bioinformatics 2005; 21, 3674-76.

[23] S Götz, JM García-Gómez, J Terol, TD Williams, SH Nagaraj, MJ Nueda, M Robles, M Talón, J Dopazo and A Conesa. High-throughput functional annotation and data mining with the Blast2GO suite. Nucleic. Acids. Res. 2008; 36, 3420-35.

[24] H Guo, CX Ye, AL Wang, JA Xian, SA Liao, YT Miao and SP Zhang. Trascriptome analysis of the Pacific white shrimp Litopenaeus vannamei exposed to nitrite by RNA-seq. Fish Shellfish Immunol. 2013; 35, 2008-16.

[25] MW Pfaffl. A new mathematical model for relative quantification in real-time RT-PCR. Nucleic. Acids Res. 2001; 29, 1-6.

[26] MW Pfaffl, GW Horgan and L Dempfle. Relative expression software tool (RESTC) for group-wise comparison and statistical analysis of relative expression results in real-time PCR. Nucleic. Acids Res. 2002; 30, 1-10.

[27] JP Baren, GD Stewart, A Stokes, K Gray, CJ Pennington, R O'Neill, DAC Deans, S PatersonBrown, ACP Riddick, DR Edwards, KCH Fearon, JA Ross and RJE Skipworth. mRNA profiling of the cancer degradome in oesophago-gastric adenocarcinoma. Br. J. Canc. Manag. 2012; 107, 14349.

[28] JD Neve, O Thas, JP Ottoy and L Clement. An extension of the Wilcoxon-Mann-Whitney test for analyzing RT-qPCR data. Stat. Appl. Genet. Mol. Biol. 2013; 12, 333-46.

[29] A Oshlack, MD Robinson and MD Young. From RNA-seq reads to differential expression results. Genome. Biol. 2010; 11, 1-10.

[30] Z Wang, M Gerstein and M Snyder. RNA-Seq: A revolutionary tool for transcriptome. Nat. Rev. Genet. 2009; 10, 1-7.

[31] JRO Cesar, B Zhao, S Malecha, H Ako and J Yang. Morphological and biochemical changes in the muscle of the marine shrimp Litopenaeus vannamei during the molt cycle. Aquaculture 2006; 261, 688-94.

[32] X Fu, N Fu, S Guo, Z Yan, Y Xu, H Hu, C Menzel, W Chen, Y Li, R Zeng and P Khaitovich. Estimating accuracy of RNA-Seq and microarrays with proteomics. BMC Genomics 2009; 10, 1-12.

[33] S Xue, Y Liu, Y Zhang, Y Sun, X Geng and J Sun. Sequencing and de novo analysis of the hemocytes transcriptome in Litopenaeus vannamei response to white spot syndrome virus infection. PLoS One 2013; 8, 1-12.

[34] QY Zhao, Y Wang, YM Kong, D Luo, X Li and P Hao. Optimizing de novo transcriptome assembly from short-read RNA-Seq data: A comparative study. BMC Bioinformatics 2011; 12, 1 12.

[35] D Zeng, X Chen, D Xie, Y Zhao, C Yang, Y Li, N Ma, M Peng, Q Yang, Z Liao, H Wang and X Chen. Transcriptome analysis of Pacific white shrimp (Litopenaeus vannamei) Hepatopancreas in response to taura syndrome virus (TSV) experimental infection. PLoS One 2013; 8, 1-8.

[36] C Li, S Weng, Y Chen, X Yu, L Lü, H Zhang, J He and X Xu. Analysis of Litopenaeus vannamei transcriptome using the next-generation DNA sequencing technique. PLoS One 2012; 7, 1-12.

[37] J Pines and T Hunter. Cyclins A and B1 in the human cell cycle. Ciba. Found. Symp. 1992; 170, 187-96.

[38] CF Lehner and PH O'Farrell. The roles of drosophila cyclins A and B in mitotic control. Cell 1990; 61, 535-47. 
http://wjst.wu.ac.th

[39] V Visudtiphole, S Klinbunga and K Kirtikara. Molecular characterization and expression profiles of cyclin A and cyclin B during ovarian development of the giant tiger shrimp Penaeus monodon. Comp. Biochem. Physiol. A Mol. Integr. Physiol. 2009; 152, 535-43.

[40] L Qiu, S Jiang, F Zhou, J Huang and Y Guo. Molecular cloning and characterization of a cyclin B gene on the ovarian maturation stage of black tiger shrimp (Penaeus monodon). Mol. Biol. Rep. 2007; 24, 24.

[41] N Perrimon, L Engstrom and AP Mahowald. A pupal lethal mutation with a paternally influenced maternal effect on embryonic development in Drosophila melanogaster. Dev. Biol. 1985; 110, 48091.

[42] M Furriols and J Casanova. In and out of Torso RTK signalling. EMBO J 2003; 22, 1947-52.

[43] G Jiménez, A Guichet, A Ephrussi and J Casanova. Relief of gene repression by torso RTK signaling: Role of capicua in Drosophila terminal and dorsoventral patterning. Gene. Dev. 2000; 14, 224-31.

[44] P Li, K Wood, H Mamon, W Haser and T Roberts. Raf-1: A kinase currently without a cause but not lacking in effects. Cell 1991; 64, 479-82.

[45] ZB Yu, CK Mu, WW Song, RH Li, YE Chen and CL Wang. Screening of genes related to ovarian development in the swimming crab, Portunus trituberculatus, by suppression subtractive hybridization. Genet. Mol. Res. 2015, 14, 18675-86.

[46] XJ Du, JX Wang, N Liu, XF Zhao, FH Li and JH Xiang. Identification and molecular characterization of a peritrophin-like protein from fleshy prawn (Fenneropenaeus chinensis). Mol. Immunol. 2006; 43, 1633-44.

[47] L Wang, F Li, B Wang and J Xiang. A new shrimp peritrophin-like gene from Exopalaemon carinicauda involved in white spot syndrome virus (WSSV) infection. Fish Shellfish Immunol. 2013; 35, 840-46.

[48] M Khayat, PJ Babin, B Funkenstein, M Sammar, H Nagasawa, A Tietz and E Lubzens. Molecular characterization and high expression during oocyte development of a shrimp ovarian cortical rod protein homologous to insect intestinal peritrophins. Biol. Reprod. 2001; 64, 1090-99.

[49] Y Chen, T Souaiaia and T Chen. PerM: Efficient mapping of short sequencing reads with periodic full sensitive spaced seeds. Bioinformatics 2009; 25, 2514-21.

[50] YK Kim, N Tsutsui, I Kawazoe, T Okumura, $\mathrm{T}$ Kaneko and $\mathrm{K}$ Aida. Localization and developmental expression of mRNA for cortical rod protein in kuruma prawn Marsupenaeus japonicus. Zool. Sci. 2005; 22, 675-80.

[51] W Loongyai, JC Avarre, M Cerutti, E Lubzens and W Chotigeat. Isolation and functional characterization of a new shrimp ovarian peritrophin with antimicrobial activity from Fenneropenaeus merguiensis. Mar. Biotechnol. 2007; 9, 624-37. 